\title{
THE LEARNING OF SEXUAL ABUSE PREVENTION CONCEPTS AND THE RELIABILITY OF THE CKAQ-RIII IN THE SOUTH AFRICAN CONTEXT
}

\section{Munita Dunn}

\section{INTRODUCTION}

Prevention is said to be better than cure and while no one could disagree with this sentiment in theory, there seems to be some difficulty in implementing it in practice. Western society embraces the romantic vision that children should simply be "children". A child's obligation, it seems, is to be happy. However, the experiences of children in developing countries subvert the modern, mythologized understandings of childhood. Childhood should be a period of innocence, but sadly some children think that the abuse they experience is a normal part of childhood.

The global community is quickly coming to grips with the severity and breadth of the problems besetting today's children, especially in the field of child sexual abuse (CSA). The rapidly changing social environment makes demands not only on the family and on the individual, but also on educational institutions (De Witt, 2009:287). However, most professionals who work in the field of child protection note that there is an under-reporting of sexual abuse by children and their families (Van Niekerk, 2006:101). Lewis (1999:123) reports that the shortcomings of the South African criminal justice system, represented by the police and courts, aggravate the problem of violence. Because of insensitive and judgmental behaviour among adults, child victims of sexual abuse refrain from reporting. Spies (2006:52) adds that children whose attempts at disclosure are disbelieved, or who do not have confidence in parental protection after disclosure, may keep their secret into adulthood. This discrepancy makes essential the role of prevention and early detection of CSA and therefore presents a major challenge to society and to professionals dealing specifically with children.

This purpose of this article is twofold. Firstly, it aims to explore the concept of sexual abuse prevention, with specific reference to the Hands Off Our Children (HOOC) school-based CSA prevention programme, and as part of this exploration it also investigates whether the implementation of the HOOC board game significantly increased Grade 4 learners' knowledge levels about sexual abuse prevention concepts. Secondly, it aims to discuss the reliability of the American-based Children's Knowledge of Abuse Questionnaire-Revised (CKAQ-RIII) (Tutty, 1992) as an instrument to determine the knowledge levels of sexual abuse prevention concepts within the South African context. The terms "sexual abuse prevention concepts" and "body awareness" will be used interchangeably throughout this article.

\section{CHILD ABUSE IN SOUTH AFRICA}

South Africa today is a country that promotes democracy and a culture of human rights. Yet violence against women and children has unfortunately reached epidemic proportions in South Africa. A high percentage of our communities are classified as "disadvantaged". Marshall and Herman (2000:59) state that the following might be typical characteristics of the circumstances that prevail for approximately $70 \%$ of the South African population: 
- High unemployment rate;

- Poor and overcrowded educational facilities;

- High incidence of single parenting;

- Squatter accommodation or council buildings;

- No recreational or educational facilities;

- High rates of sexual abuse of children - particularly girls;

- Minimal parenting skills;

- High stress levels because of poverty;

- High rates of domestic violence;

- Very little parental support from fathers - either financial or physical;

- High levels of violence and crime amongst men;

- Overcrowded accommodation;

- Few state security or social welfare services.

These characteristics emphasise the fact that the opportunities for child abuse are created by the conditions of the children's lives. These conditions include a lack of parental love as well as the fact that parents that are working and leave children unattended for long periods of time. The opportunity for rape is aggravated by the number of unemployed men who are idle at home. Usually when parents have sex in the presence of children, this would be regarded as a form of sexual abuse. But for many families in South Africa this does not apply. Parents simply do not have a choice as many of the sub-economic houses and informal shelters do not provide privacy (Marshall \& Herman, 2000:59-62). The researcher raises the question of whether the definitions of child abuse should be adapted to accommodate the circumstances of these impoverished families.

\section{PREVENTION}

\section{Defining prevention}

Prevention can be described as an active intervention plan comprised of various components with the ultimate goal of averting or avoiding a negative outcome, in this case, sexual abuse (Plummer in Schutte, 2000:8). Mayes et al. (in Schutte, 2000:8) add that preventing abuse can be seen as a process of altering the potential perpetrator, the potential victim or the environment in which both exist. For the purpose of this article prevention refers to the intervention that will attempt either to prevent the phenomenon of child sexual abuse, or to prevent further occurrence of the sexual abuse.

In South Africa, unfortunately, little research has been done on effective prevention programmes to combat child sexual abuse. Child protection services in South Africa have always been severely under-resourced. Growing public awareness of child abuse has not been accompanied by a corresponding increase in funding for the overstretched structures that are expected to respond to the problem. Typically, child protection organisations, as part of the historically marginalised social service sector, lack the basic resources and programme components that are required to deal effectively with child abuse (Loffell, 2000:6). 


\section{Prevention strategies}

From the moment that children start speaking they are taught about themselves and the world around them. This information is crucial to developing children who are able to question information that they are given. By virtue of their size and economic status, children will mostly be dependent on someone else for protection - whether it is an adult or an adolescent within the child's family context. Protective mechanisms for children have to be built in by empowering them to stand up for themselves, by allowing them to be children and by legislating for lawful protection. Child abuse prevention work is about challenging those conditions that create children's vulnerability in the home and in society (Marshall \& Herman, 2000:77).

Prevention can be classified into three subsets, namely primary, secondary and tertiary prevention. This classification provides a context for the various prevention efforts. There is, however, an overlap between these areas and particular prevention strategies can fall into more than one category (Helfer in McGregor, 1993:61). For the purpose of this article, only primary prevention will be discussed briefly.

\section{Primary prevention}

Primary prevention will first be defined and then discussed briefly. Primary prevention is defined by Schutte (2000:8) as the efforts targeted at the populations who have been least affected by the problem. The broader population is targeted in the hope that they have not yet been confronted with the problem and that they will be able to take a stand against it if faced with it in the future. According to McGregor (1993:61), one of the main aspects of primary prevention is to focus on the individual with the purpose of preventing abuse from ever occurring to that individual. Lab (in Davis \& Campher, 2008:142) emphasises the proactive nature of primary prevention.

Primary prevention at educational institutions tends to take place in the form of school-based intervention programmes that aim to equip the child with self-protection skills. These programmes focus on different age groups and developmental levels - from pre-schoolers, through early and middle childhood, to adolescents (McGregor, 1993:61). Such programmes share certain common features:

- An attempt to broaden the child's concept of sexual abuse and understanding it;

- To alert the child to the possibility that someone may try to abuse him/her;

- An attempt to broaden children's views as to who the abusers might be - especially to move beyond the original concept of "Stranger Danger", and to emphasise making children aware that danger is more likely to come from someone they know, possibly even a family member;

- An attempt to broaden the child's knowledge about the various possible actions they can take to protect themselves (McGregor, 1993:61).

By far the majority of prevention efforts have been directed at this type of primary prevention, namely equipping children with self-protection skills. Such programmes are usually presented to children in school settings by teachers or private outside agencies which come into schools for a period of time. Schutte (2000:8) states that one of the most common strategies to combat sexual abuse has been the provision of classroom-based instruction for children of all ages on how to protect themselves from sexual assault and what to do if they experience actual abuse, 
or are faced with potential abuse. The HOOC campaign, launched in the Western Cape, is an example of such a programme.

\section{THE HOOC CAMPAIGN AS A SOUTH AFRICAN SCHOOL-BASED INTERVENTION PROGRAMME}

The Hands Off Our Children - Your Child is My Child campaign (HOOC) was the initiative of Minister Leonard Ramatlakane, Minister of Community Safety, Western Cape Government. The campaign has as its purpose to create support and awareness, to mobilise all relevant roleplayers to fulfil their roles and to assist in preventing child abuse from occurring. Another goal of the campaign is empowering children with knowledge about preventative concepts to prevent this crime from happening to them. The Minister launched the HOOC campaign in the Western Cape on 15 March 2002. The programme was launched in the Western Cape schools on 13 February 2003 and ended in June 2004 (Hanekom, 2002:2).

The HOOC campaign consisted of several intervention strategies - the school-based programme being one of them. The school programmes catered for learners of all ages and included an educational crime prevention puppet show for the foundation phase learners. There was a separate child protection drama for the pre-school to Grade 2 learners dealing with key issues on child abuse (Hanekom, 2003). A colouring book with messages about child abuse prevention was distributed.

A video about child abuse was screened and used in a group discussion with learners in Grades 3 to 5. The HOOC project aimed to reinforce self-protective concepts by providing each Grade 4 learner with a board game that had a preventative focus. The HOOC board game was therefore used as part of a school-based programme. Grade 6 and 7 learners were educated on abuse, drugs and alcohol by means of the Lions/Quest for Adolescence life skills programme. Each child in the Western Cape received an HOOC wristband (Hanekom, 2003).

In conclusion, HOOC aimed to protect children against all forms of abuse and neglect through accessible, integrated and co-ordinated services focusing on primary, secondary and tertiary prevention, intervention and rehabilitation, based on a multidisciplinary inter-sectoral approach, taking into account the particular context of each child in the Western Cape. The HOOC board game will be discussed next.

\section{The HOOC board game}

The board game was developed by the researcher - based on the concept of the snake-andladders board game with questions and dice. The questions are developmentally appropriate and based on prevention concepts against child sexual abuse. The board game is the size of an A4 page with a cartoon-like figure printed on it. The figurine's body is coloured according to the traffic light concept. These colours indicate areas for appropriate and inappropriate touching on the body. Red areas indicate danger zones, orange areas indicate cautionary zones and green areas indicate safe zones. The figurine's body is divided into 38 blocks with different categories. The aim of the game is to proceed from the first block to the last block. The player who arrives there first is the winner (Dunn, 2004).

There are three different categories of blocks. The first category is blocks with information statements - the player needs to indicate whether the statement is true or false. The second category is blocks with questions - the player needs to answer the questions. The third category is blocks known as "remember blocks" - these blocks contain information the player must read aloud and try to remember. For a correct answer, the player can move two blocks ahead. For an 
incorrect answer, the player must move back one block. One to six players can play the board game. The board game is available in Afrikaans, English and isiXhosa (Dunn, 2004). Figure 1 gives a visual representation of the board game.

\section{FIGURE 1 THE HOOC BOARD GAME}

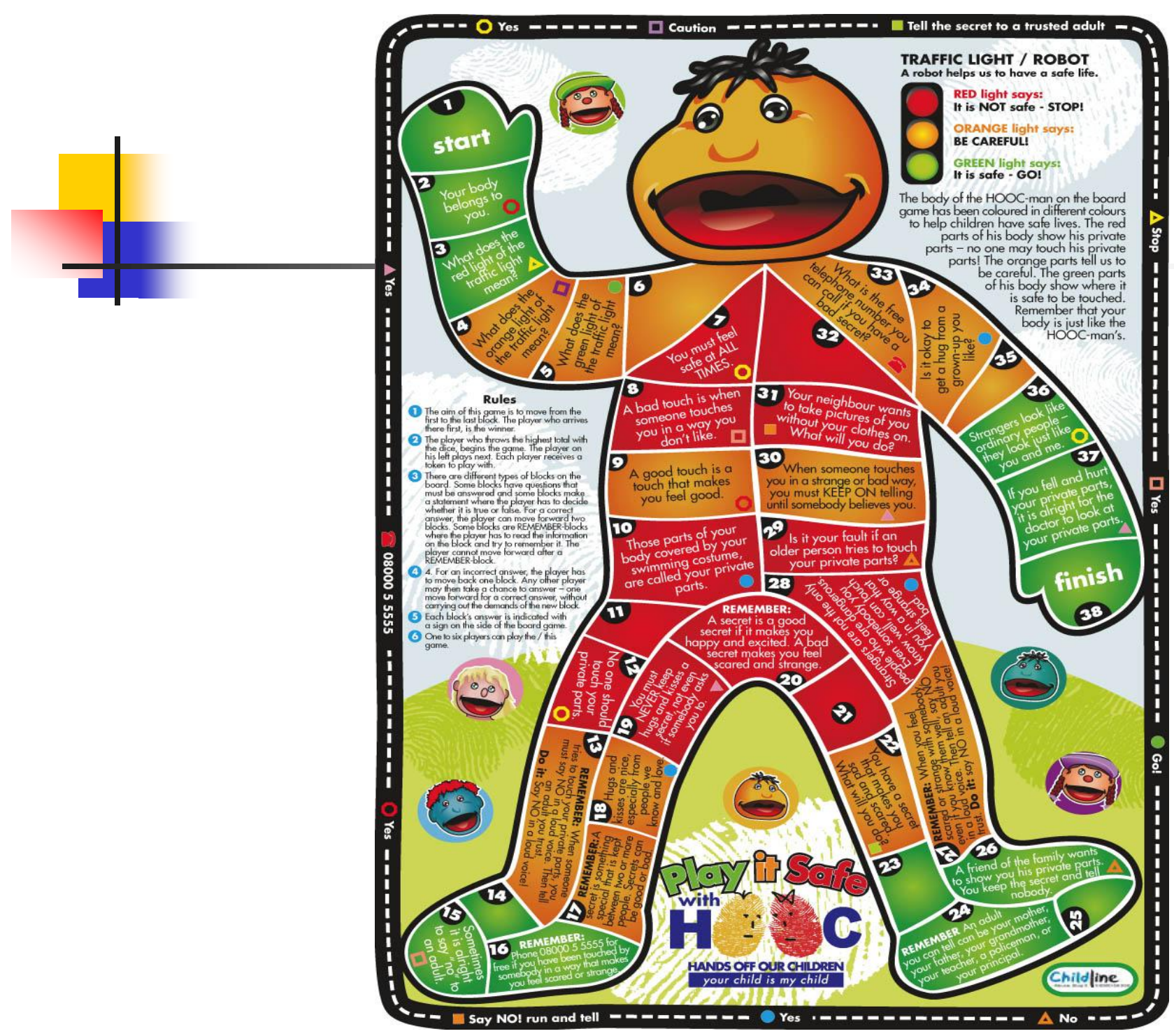

The CKAQ-RIII was used to assess the levels of knowledge obtained on sexual abuse prevention concepts.

\section{THE CHILDREN'S KNOWLEDGE OF ABUSE QUESTIONNAIRE-REVISED (CKAQ-RIII)}

The standardised Children's Knowledge of Abuse Questionnaire (CKAQ) was developed by Tutty (1992) to assess the knowledge levels of sexual abuse prevention concepts of children aged 6 to 12. Tutty (2000:283) adds that the scale was developed to test the major sexual abuse prevention concepts offered by a range of programmes rather than being programme-specific. 
An extensive review of child abuse prevention programmes and research provided information for the construction of the items. The CKAQ was designed so that children with no previous exposure to prevention materials could understand the questions. The instructions provide a description of good, bad and confusing touches since, without this information, the questions could not be understood by children with no previous exposure to prevention concepts. It must be noted, however, that the information contained in the instructions constitutes a mini-lecture on prevention and might have influenced children's scores on subsequent usage of the measure (Tutty, 1992:375).

The test utilises a true-false format. The CKAQ originally consisted of 35 items; however, another five more "complex" items were added for children in Grades 3 and 6 to avert concerns about a possible ceiling effect. It begins with items about assertiveness with peers, non-sexual touching and attitudes regarding strangers. These areas were expected to be relatively familiar to children and were intended to establish a comfortable initial response to the questionnaire. Items in reference to sexual abuse and the possibility that familiar people might touch children in confusing or uncomfortable ways were situated toward the end of the measure (Tutty, 1992:375; Tutty, 1994:184).

In order to compensate for younger children's lack of reading ability at the appropriate level, the CKAQ is usually administered verbally and individually to the lower grades. To ensure comparable results, the test must also then be administered verbally to learners in the higher grades (Tutty, 1994:184). The CKAQ was revised by Tutty (1997:873) to 33 items. The revised scale consists of Inappropriate and Appropriate Touch Subscales. The former includes concepts that represent the major focus of most abuse prevention programmes: different kinds of touch and permission for children to tell if they are uncomfortable, for example (Tutty, 2000:283). The questionnaire has been revised on several occasions since its initial development and is currently known as the CKAQ-RIII. The CKAQ-RIII has strong psychometric properties. The revised version incorporates a new 9-item subscale on Appropriate Touch, including such issues as the fact that sometimes doctors may need to see a child's private parts and that, if lost, it is appropriate for the child to ask a security guard for help, even if he is a stranger. The 24item Inappropriate Touch Subscale consists of the strongest items identified by factor analysis from the 40-item original scale.

The internal consistency $(K R-20)$ is an alpha of .87 , strong internal reliability. Item-tocorrected-total correlations were above .300 , clearly in the range suggested as acceptable by Nunnally (in Tutty, 1997:873). One month test-retest reliability was established as .88. Norms for the Inappropriate Subscale show no significant differences in scores on the basis of gender for any age-group of children, nor was the overall effect of gender significant. Differences on the basis of age did, however, reach statistical significance in that the younger children had consistently lower scores on the measure than older children (Tutty, 1997:873).

Tutty (1994:186) also states that the pre-test with the CKAQ-R does not sensitise children so that improvements on the post-test is merely a matter of practice. She conducted a study on a large group of children who demonstrated that improvements on the post-test are not simply a result of having been administered the CKAQ previously. To date, there are psychometric data only on the Inappropriate Touch Subscale.

The researcher used the 33 items of the CKAQ-RIII as part of the questionnaire compiled for this study. As the CKAQ-RIII is an American standardised questionnaire, it is important to establish the reliability of this questionnaire for the South African context. 


\section{RESEARCH METHODOLOGY}

\section{Objectives}

The major objectives of this study were:

- to provide a theoretical foundation on prevention strategies and the learning of sexual abuse concepts by a thorough literature review;

- to determine whether there is a significant difference in the improvement of knowledge between the experimental and the control groups after the implementation of the board game;

- to determine the reliability of the CKAQ-RIII in the South African context.

\section{Research approach}

A combined quantitative-qualitative approach known as intervention research was used in the study. Intervention research is a phase model consisting of six phases and each phase in its turn comprises a series of steps. Intervention research is defined as studies carried out for the purpose of conceiving, creating and testing innovative human service approaches to prevent or ameliorate problems, or to maintain quality of life (De Vos, 2002:396). According to Rothman and Thomas (1994:3), there appear to be three main types of endeavours that reflect that intent: intervention knowledge development (KD), intervention knowledge utilisation (KU), and lastly, intervention design and development (D\&D). Although these approaches differ in some respects, they also share common features, including in particular a set of steps of interconnected activities that are intended to guide researchers and practitioners to develop innovative interventions for effecting change in problem situations that relate to human service. Intervention design and development (D\&D) was used for this study.

Intervention design and development (D\&D) embraces several different approaches that seek to construct a systematic methodology for evolving human services intentions. D\&D is paramount in the process as it is the point at which innovative human service intentions are evolved, and it is often the culminating activity that the other facets precede and lead up to. D\&D has its own objectives, methods and results. This facet of intervention research can be carried out as an independent enterprise, except for KU that generally occurs in the formative stages of most D\&D projects (Rothman \& Thomas, 1994:7). The D\&D model is a phase model consisting of six phases, according to De Vos (2002:397):

- Problem analysis and project planning;

- Information gathering and synthesis;

- Design;

- Early development and pilot testing;

- Evaluation and advanced development;

- Dissemination.

\section{Type of research}

The author used applied research within the intervention research paradigm. Applied research aims to address immediate problems facing the professional in practice. The goal is the scientific planning of induced change in a troublesome situation and to develop solutions for problems and applications in practice (De Vos, 2002:108). 


\section{Hypotheses}

The following hypotheses guided this study:

Hypothesis 0: The experimental group's knowledge of body awareness does not improve significantly.

Hypothesis 1': The experimental group's knowledge of body awareness does improve significantly.

The hypotheses are applicable to the three tests conducted in the research - therefore each hypothesis refers to the pre-, post- and follow-up testing.

\section{RESEARCH PROCEDURES}

\section{Participants}

A proportionally representative sample of approximately 2000 children from the population of children between 9 and 12 years who are currently in Grade 4 in the Western Cape were selected for the control group. The 500 participants for the experimental group were randomly selected from the schools, which were contacted and visited by the comprehensive HOOC campaign. All the participants have been exposed to the HOOC campaign. The research was conducted in Afrikaans, English and isiXhosa, according to the preference of the participants.

\section{Data-gathering mechanisms}

The Children's Knowledge of Abuse Questionnaire-Revised (CKAQ-RIII) was used as psychometric instrument to obtain data on the knowledge levels of sexual abuse prevention concepts of Grade 4 children.

\section{Procedures}

The Assistant Director of Social Crime Prevention gave permission for the research to be incorporated into the HOOC campaign. The Western Cape Education Department gave permission to conduct research during school hours at the relevant schools. The principals of the relevant schools were contacted and the objectives and procedures of the research were explained to them. Permission for participation was obtained from the principals.

The researcher ensured that each school had a proper referral strategy in place to immediately assist children who disclose. Each class was randomly divided into two groups - an experimental and control group. Before the board game was played the pre-testing was conducted during one session in class format. After the pre-testing the board game was introduced to the experimental group. The board game session took place in a separate venue, each assistant intervening with a group of six learners. In an attempt to minimise external factors impacting on the children, the experimental and control groups were separated until the post-testing was completed. The learners in the experimental groups were again psychometrically assessed on the same day with the same battery, although items were sequentially varied. Refer to Table 1 for a visual representation of the data-collection phase. The experimental and control groups were again assessed after six weeks to monitor the longterm effects of the programme. For all learners parallel versions of the instrument were used in which the order of the questionnaires as well as the items were varied randomly. 
TABLE 1

DATA COLLECTION

\begin{tabular}{|l|c|c|}
\hline & Experimental $(\mathbf{n = 4 0 7})$ & Control $(\mathbf{n = 1 6 9 7})$ \\
\hline Pre-test & $*$ & $*$ \\
\hline HOOC Board Game & $*$ & \\
\hline Post-test & $*$ & $*$ \\
\hline Post-test (6 weeks) & $*$ & \\
\hline
\end{tabular}

\section{Ethical issues}

The following ethical principles were adhered to during the study.

\section{Harm to experimental respondents}

The researcher has the responsibility to protect the respondents against any possible physical and emotional harm. The respondents were thoroughly informed beforehand about the potential impact of the investigation. This offered respondents and their parents the opportunity to withdraw from the study, if they should wish to do so (Strydom, 2002:64-65).

The researcher is not aware of any physical and/or emotional harm that was done to the respondents in this study. However, the researcher remained alert and sensitive in order to act in the best interests of the respondents and meet their immediate needs. In the case of possible disclosures, the researcher had a referral strategy in place. The educators also agreed to monitor the children closely after the intervention.

\section{Informed consent}

Obtaining informed consent implies that all possible or adequate information on the goal of the study, the procedures, the possible advantages, disadvantages and dangers to which respondents may be exposed, and the credibility of the researcher must be provided to potential respondents or their legal representatives (Strydom, 2002:65). Emphasis must be placed on accurate and complete information to enhance respondents' comprehension of the study. Respondents must be legally and psychologically competent to give consent and must be aware that they may withdraw from the study at any time. The researcher had a discussion session with each principal beforehand to explain the procedures and practical implications of the study. Since class discussion on the research may influence the results and outcomes of the study, the learners were told that they are completing questionnaires on how children feel and what they think and do in a variety of situations. Adequate information was provided with regards to the demands the study would make on their time, activities and disclosure of confidential information. There was adequate opportunity for learners to ask questions before the study commenced, as well as during it. Feedback regarding the results was provided, if requested by the school.

\section{Deception of respondents}

Deception of respondents could be defined as withholding information, or offering incorrect information in order to ensure the participation of respondents when they would otherwise possibly have refused it (Corey, Corey \& Callanan, 1993:230). Neuman (in Strydom, 2002:66) adds that deception occurs when the researcher intentionally misleads subjects by way of written or verbal instructions, the actions of other people, or certain aspects of the setting. The researcher therefore did not disguise the real goals and functions of the study, as well as the possible experiences the respondents would go through. 


\section{Violation of privacy}

The right to privacy is the individual's right to decide when, where, to whom and to what extent his or her attitudes, beliefs and behaviour will be revealed (Singleton et al. in Strydom, 2002:67.) This principle can be violated in a variety of ways and it is imperative that researchers be reminded of the importance of safeguarding the privacy and identity of respondents, and that they need to act with the necessary sensitivity where the privacy of subjects is relevant. Privacy implies the element of personal privacy, while confidentiality indicates the handling of information in a confidential manner (Strydom, 2002:67.) The researcher therefore did not make use of concealed media without the knowledge and consent of the respondents. All data were treated as confidential.

\section{Debriefing of respondents}

The problem may sometimes arise that respondents could benefit and get involved in the therapy or research to such an extent that they may suffer harm on completion of the programme. After the completion of the study, the researcher has to rectify any misperceptions which may have arisen in the minds of the respondents (Strydom, 2002:73). The researcher handled termination of the research with sensitivity. The researcher was willing to organise debriefing sessions for the respondents to complete the learning experience. This, however, proved not to be necessary.

\section{Statistical techniques and methods of analysis}

The data were collected in a primarily quantitative way. The relationships between various variables were observed. The relationship between the pre-tests of the control and experimental groups concerning knowledge of body awareness was established by using analysis of variance (ANOVA). The relationship between the follow-up test scores between the control and experimental groups, as well as the relationship between control group's scores on the pre- and follow-up tests, was also established by using analysis of variance (ANOVA). ANOVA is a statistical analysis used when more than two groups are being investigated and it is employed to ascertain significant differences between groups (Wilkinson \& McNeil, 1996:415). The analyses were done by using the Statistical Package for Social Science (SPSS) (George \& Mallery, 1999).

TABLE 2

SAMPLE DESCRIPTION $(\mathbf{N}=1697)$

\begin{tabular}{|l|l|}
\hline Characteristics of Sample & \\
\hline Control Group $(\mathbf{n}=\mathbf{1 2 9 0})$ & \\
Mean Age & 9.68 years \\
Gender & $52.6 \%$ \\
Male & $47.4 \%$ \\
Female & \\
Language & $48.0 \%$ \\
Afrikaans & $15.0 \%$ \\
English & $37.0 \%$ \\
IsiXhosa & \\
Ethnic Grouping & $20.8 \%$ \\
White & $38.8 \%$ \\
Coloured & $40.4 \%$ \\
\hline Black & \\
\hline
\end{tabular}




\begin{tabular}{|l|l|}
\hline Experimental Group $(\mathbf{n}=\mathbf{4 0 7})$ & 9.61 years \\
Mean Age & \\
Gender & $48.2 \%$ \\
Male & $51.8 \%$ \\
Female & $48.9 \%$ \\
Language & $17.9 \%$ \\
Afrikaans & $33.2 \%$ \\
English & \\
IsiXhosa & $18.2 \%$ \\
Ethnic Grouping & $44.5 \%$ \\
White & $37.3 \%$ \\
Coloured & \\
Black & \\
\hline
\end{tabular}

\section{ANALYSIS OF RESULTS}

\section{Sample characteristics}

Table 2 provides an overview of the general demographics of the sample. The total sample $(\mathrm{N}=1697)$, consisting of 20 primary schools, was divided into an experimental group $(\mathrm{n}=407)$ and a control group $(n=1290)$. The experimental group accounts for $24 \%$ of the population and the control group for $76 \%$.

Before the commencement of the discussion of hypotheses testing, it is imperative to determine the level of knowledge of the experimental and control groups prior to any intervention. The groups' performance on the pre-test has a significant influence on the discussion of the hypotheses.

\section{The pre-test scores for the experimental and control groups}

The knowledge of body awareness is divided into two subscales - the Appropriate Touch Subscale and the Inappropriate Touch Subscale. The learners can obtain a total score of 9 for the Appropriate Touch Subscale and a total score of 24 for the Inappropriate Touch Subscale. The results of the experimental and control groups will be discussed according to their results on the two scales.

Table 3 illustrates the analysis of variance of the pre-test scores for the experimental and control groups concerning knowledge of body awareness.

TABLE 3

ANALYSIS OF VARIANCE OF PRE-TEST SCORES OF KNOWLEDGE OF BODY AWARENESS FOR EXPERIMENTAL AND CONTROL GROUPS

\begin{tabular}{|l|l|c|c|c|c|c|}
\hline Subscale & Group & $\mathbf{n}$ & $\bar{X}$ & SD & Df & F \\
\hline Appropriate Touch & Control & 1289 & 5.23 & 2.03 & 1 & .219 \\
\hline & Experimental & 407 & 5.28 & 1.95 & 1694 & \\
\hline Inappropriate Touch & Control & 1289 & 11.93 & 3.73 & 1 & $6.123^{*}$ \\
\hline & Experimental & 407 & 12.46 & 3.70 & 1694 & \\
\hline
\end{tabular}

$* \mathrm{p}<0.05$ 
According to the results obtained shown in Table 3, it is clear that the F-value for the Appropriate Touch Subscale is not significant ( $p>0.05)$. No significant correlation exists for the pre-test scores on the Appropriate Touch Subscale between the control and experimental groups. On the Inappropriate Touch Subscale there is a significant correlation between the control and experimental groups as the F-value is significant $(\mathrm{p}<0.05)$. It seems that on the pretest of the Appropriate Touch Subscale the control and experimental groups are on the same knowledge level. On the pre-test of the Inappropriate Touch Subscale the experimental group has significantly more knowledge concerning inappropriate touching than the control group.

\section{Descriptive statistics}

\section{The experimental group and improvement of knowledge of body awareness}

The discussion will be divided into the Appropriate Touch Subscale results and the results obtained on the Inappropriate Touch Subscale. Table 4 illustrates the results of the experimental group on the pre-, post- and follow-up tests.

\section{TABLE 4}

RESULTS OF THE EXPERIMENTAL GROUP AND KNOWLEDGE OF BODY AWARENESS

\begin{tabular}{|l|c|c|c|}
\hline & n & $\bar{X}$ & SD \\
\hline Pre-Test Appropriate & 407 & 5.28 & 1.951 \\
\hline Post-Test Appropriate & 406 & 5.81 & 2.034 \\
\hline Follow-up Test Appropriate & 373 & 5.61 & 2.044 \\
\hline Pre-Test Inappropriate & 407 & 12.46 & 3.698 \\
\hline Post-Test Inappropriate & 406 & 14.13 & 4.026 \\
\hline Follow-up Test Inappropriate & 373 & 14.06 & 4.148 \\
\hline
\end{tabular}

The experimental group's knowledge of appropriate touching started at a mean of 5.28, increased to 5.81 after the intervention and decreased to 5.61 after six weeks. According to Table 4, there was an increase of knowledge concerning appropriate touching after the implementation of the HOOC board game.

The experimental group's knowledge for inappropriate touching commenced at a mean of 12.46 and improved to 14.13 after the HOOC board game. The Grade 4 learners' knowledge concerning inappropriate touching decreased slightly after six weeks to 14.06. According to Table 4, the Grade 4 learners' knowledge about inappropriate touching increased after the intervention and increased slightly during the subsequent six-week period.

\section{The control group and improvement of knowledge of body awareness}

Table 5 presents the results of the control group on the pre- and follow-up tests. As there was no intervention in the form of the HOOC board game, no post-test was conducted.

The decrease in the control group's knowledge of body awareness on the Appropriate Touch Subscale is evident in Table 5. The control group's pre-test on their knowledge of appropriate touching started at a mean of 5.23 but decreased to 4.97 after a period of six weeks without any intervention. The control group received no intervention in the form of the HOOC board game. However, the knowledge about inappropriate touching of the Grade 4 learners in the control group still increased from a mean of 11.93 to 12.94 . 
TABLE 5

RESULTS OF THE CONTROL GROUP ON KNOWLEDGE OF BODY AWARENESS

\begin{tabular}{|l|c|c|c|}
\hline & $\mathbf{n}$ & $\bar{X}$ & SD \\
\hline Pre-Test Appropriate & 1289 & 5.23 & 2.032 \\
\hline Follow-up Test Appropriate & 1152 & 4.97 & 2.132 \\
\hline Pre-Test Inappropriate & 1289 & 11.93 & 3.730 \\
\hline Follow-up Test Inappropriate & 1156 & 12.94 & 4.236 \\
\hline
\end{tabular}

\section{Inferential statistics}

Pairwise comparisons: The pre-, post- and follow-up tests of the experimental group on the appropriate touch subscale

Table 6 provides the results of the Pairwise Comparisons of the improvement of knowledge of body awareness between the pre-, post- and follow-up tests of the experimental group on the Appropriate Touch Subscale.

TABLE 6

PAIRWISE COMPARISONS: EXPERIMENTAL APPROPRIATE TOUCH SUBSCALE

\begin{tabular}{|l|l|c|}
\hline & Test & P \\
\hline Pre-Test & Post-Test & 0.000 \\
\hline Post-Test & Follow-up Test & 0.002 \\
\hline & Pre-Test & 0.000 \\
\hline Follow-up Test & Follow-up Test & 0.015 \\
\hline & Pre-Test & 0.002 \\
\hline
\end{tabular}

Table 6 represents the three tests conducted within the experimental group to determine whether or not their results differed significantly over time. According to Table 6 the pre-, post and follow-up tests of the Appropriate Touch Subscale correlate significantly $(p<0.05)$.

Results of repeated measures on the pre-, post- and follow-up tests of the experimental group on the Inappropriate Touch Subscale

Table 7 introduces Pairwise Comparisons of the measures over time on the Inappropriate Touch Subscale within the experimental group.

TABLE 7

PAIRWISE COMPARISONS: EXPERIMENTAL INAPPROPRIATE TOUCH SUBSCALE

\begin{tabular}{|l|l|c|}
\hline & Test & P \\
\hline Pre-Test & Post-Test & 0.000 \\
\hline & Follow-up Test & 0.000 \\
\hline Post-Test & Pre-Test & 0.000 \\
\hline & Follow-up Test & 0.794 \\
\hline Follow-up Test & Pre-Test & 0.000 \\
\hline & Post-Test & 0.794 \\
\hline
\end{tabular}


Table 7 represents the three tests conducted within the experimental group of the present study to determine whether or not their results differed significantly over time. According to Table 7, the pre- and post-tests of the Inappropriate Touch Subscale correlate significantly $(\mathrm{p}<0.05)$. The pre- and follow-up tests of the Inappropriate Touch Subscale also correlate significantly $(\mathrm{p}<0.05)$. There is, however, no significant correlation between the post- and follow-up tests. $(\mathrm{p}>0.05)$.

\section{Analysis of variance of the control group's scores on the pre- and follow-up tests}

Table 8 illustrates the analysis of variance of the control group's pre- and follow-up test scores concerning knowledge of body awareness.

TABLE 8
ANALYSIS OF VARIANCE OF CONTROL GROUP'S SCORES ON THE PRE- AND
FOLLOW-UP TESTS
\begin{tabular}{|l|l|c|c|c|c|c|}
\hline Subscale & Group & n & $\bar{X}$ & SD & df & p \\
\hline Appropriate Touch & Pre-Test & 1151 & 5.21 & 2.021 & 1150 & 0.000 \\
\hline & Follow-up Test & 1151 & 4.97 & 2.130 & & \\
\hline Inappropriate Touch & Pre-Test & 1155 & 11.83 & 3.746 & 1154 & 0.000 \\
\hline & Follow-up Test & 1155 & 12.94 & 4.238 & & \\
\hline
\end{tabular}

Table 8 represents the results obtained by the control group to assess whether there was a significant difference in the knowledge of body awareness between the pre-test and follow-up test. According to Table 8, there was a significant decrease in knowledge of body awareness on the Appropriate Touch Subscale. However, there was a significant increase in knowledge of body awareness in the Inappropriate Touch Subscale. Whilst the mean scores for the knowledge on appropriate touching decreased, the mean scores for the knowledge on inappropriate touching increased. It seems that the control group was positively influenced on the inappropriate body awareness knowledge, although no intervention was implemented.

The analysis of variance of follow-up test scores of knowledge of body awareness for the experimental and control groups

Table 9 illustrates the analysis of variance of the follow-up test scores for the experimental and control groups concerning knowledge of body awareness.

TABLE 9

ANALYSIS OF VARIANCE OF FOLLOW-UP TEST SCORES OF KNOWLEDGE OF BODY AWARENESS FOR EXPERIMENTAL AND CONTROL GROUPS

\begin{tabular}{|l|l|c|c|c|c|c|}
\hline Subscale & Group & $\mathbf{N}$ & $\bar{X}$ & SD & df & F \\
\hline Appropriate Touch & Control & 1152 & 4.97 & 2.13 & 1 & $26.177^{* *}$ \\
\hline & Experimental & 373 & 5.61 & 2.04 & 1523 & \\
\hline Inappropriate Touch & Control & 1156 & 12.94 & 4.24 & 1 & $19.898^{* *}$ \\
\hline & Experimental & 373 & 14.06 & 4.15 & 1527 & \\
\hline
\end{tabular}

$* * \mathrm{p}<0.01$

Table 9 represents the results obtained by the control and experimental groups in the follow-up test to determine whether or not their knowledge improved significantly. Since the F-values are 
significant $(\mathrm{p}<0.01)$, it is clear that there is a significant difference in the improvement of knowledge on the two subscales within the control and experimental groups. The follow-up test scores indicate that on the Appropriate Touch Subscale the experimental group scored significantly higher than the control group. On the Inappropriate Touch Subscale the experimental group also scored significantly higher than the control group.

The experimental group thus seems to be on a higher level of knowledge after a duration of six weeks without an intervention than the control group. The duration of knowledge for the experimental group is significantly more than that of the control group. In the light of the abovementioned results, the null hypothesis is rejected, as there is a significant improvement in the experimental group's knowledge of body awareness. Hypothesis $1^{1}$ is thus not rejected.

\section{THE RELIABILITY OF THE CKAQ-RIII}

For the purpose of establishing reliability of the CKAQ-RIII for the study, the test-retest method has been used. Table 10 demonstrates the Pearson Correlation Coefficient Results on the results of the Appropriate Touch Subscale of the CKAQ-RIII as conducted during the pre-, post- and follow-up tests.

TABLE 10

PEARSON CORRELATION COEFFICIENT RESULTS BETWEEN THE PRE-, POSTAND FOLLOW-UP TESTS WITH THE CKAQ-RIII APPROPRIATE TOUCH SUBSCALE

\begin{tabular}{|l|c|c|}
\hline Test & Pre-Test Appropriate & Follow-up Test Appropriate \\
\hline Post-Test Appropriate & $0.553 * *$ & $0.541 * *$ \\
\hline$* * \mathrm{p}<0.01$ & \multicolumn{2}{|c|}{}
\end{tabular}

According to Table 10, the Pearson correlation coefficient between the scores on the pre-test and the post-test on the Appropriate Subscale of the CKAQ-RIII is statistically significant $(r=$ $0.553 ; \mathrm{p}<0.01)$. The coefficient between the scores on the post-test and follow-up test on the Appropriate Subscale of the CKAQ-RIII is also statistically significant $(r=0.541 ; \mathrm{p}<0.01)$.

Table 11 illustrates the Pearson Correlation Coefficient Results on the results of the Inappropriate Touch Subscale of the CKAQ-RIII as conducted during the pre-, post- and follow-up tests.

TABLE 11

PEARSON CORRELATION COEFFICIENT RESULTS BETWEEN THE PRE-, POSTAND FOLLOW-UP TESTS WITH THE CKAQ-RIII INAPPROPRIATE TOUCH SUBSCALE

\begin{tabular}{|l|c|c|}
\hline Test & Pre-Test Inappropriate & Follow-up Test Inappropriate \\
\hline Post-Test Inappropriate & $0.626^{* *}$ & $0.659 * *$ \\
\hline$* * \mathrm{p}<0.01$ & \multicolumn{2}{|l}{} \\
\hline
\end{tabular}

As can be seen in Table 11, the Pearson correlation coefficient between the scores on the pretest and post-test on the Inappropriate Touch Subscale of the CKAQ-RIII is statistically significant $(\mathrm{r}=0.626, \mathrm{p}<0.01)$. The coefficient between the post-test and the follow-up test on the Inappropriate Touch Subscale of the CKAQ-RIII is also statistically significant $(r=0.659$; $\mathrm{p}<0.01$ ). In the light of the above results, it seems that the CKAQ-RIII provides reliable and accurate measures on the Appropriate and Inappropriate Touch Subscales in the South African context. 


\section{DISCUSSION}

The empirical results will be integrated with the literature by focusing firstly on the improvement of knowledge of body awareness on the appropriate and inappropriate scales of the CKAQ-RIII, and secondly on the reliability of the CKAQW-RIII in the South African context.

\section{The improvement of knowledge of body awareness}

\section{The pre-test scores for the experimental and control groups}

According to Table 3, there is no significant correlation between the experimental and control groups on the pre-test scores of the Appropriate Touch Subscale. However, on the Inappropriate Touch Subscale there is a significant correlation between the experimental and control groups on the pre-test scores. It seems that there was no difference between the pre-test scores of the experimental and control groups concerning their knowledge of appropriate touching. Thus the two groups were on the same level of knowledge regarding appropriate touching before any interventions were implemented. On the Inappropriate Touch Subscale the experimental group had significant more knowledge on inappropriate touching than the control group. In other words, the experimental group had more knowledge before any interventions were implemented. As the group was chosen randomly, no bias could have occurred in allocating children to groups. The difference in knowledge could possibly be due to stimulation these children received at home regarding the specific topics covered in the questionnaire.

All the schools included in the study had been exposed to the Hands Off Our Children Prevention Campaign (HOOC) within six to twelve months prior to the implementation of the board game. A possible contributing factor to the difference between the experimental and control groups' level of knowledge of body awareness on the pre-test may therefore be the impact of the HOOC Prevention Campaign. However, as the researcher selected both groups using randomised sampling, each member within the population had an equal chance of being selected. Strydom and Venter (2002:209) emphasise that random sampling is the most reliable method of assuring the representation of samples. As each member of the universe had an equal chance of being selected for either the experimental or control group, the significant difference in knowledge on the Inappropriate Touch Subscale may be simply due to chance. As Wright (cited in Mouton, 1996:139) comments: "We might do all the right things, get a complete list of the population, use a table of random numbers, employ redundant safeguards and nevertheless end up with all the fat ones or all Democrats... purely by chance". The researcher thus ascribes the significant difference in knowledge to chance.

\section{The pre-, post- and follow-up test scores for the experimental group}

The Appropriate and Inappropriate Touch Subscales are discussed separately.

\section{Appropriate Touch Subscale}

Table 6 illustrates the significance between the pre-, post- and follow-up tests for the experimental group on the Appropriate Touch Subscale. There is an indication that significant differences exist between all three tests. In other words, there is a significant difference in knowledge between the pre- and post-tests, the post- and follow-up tests, as well as between the pre- and follow-up tests.

There was a significant increase in knowledge on appropriate touching within the experimental group from the pre-test to the post-test. The HOOC board game was implemented as intervention between the pre- and post-tests. However, from the post-test to the follow-up test 
six weeks later there was a significant decrease in knowledge. As there is a significant increase in knowledge from the pre-test to the follow-up test, this indicates that the Grade 4 learners still retained knowledge over the six-week period that they did not possess during the pre-testing. This has implications for the period of time and frequency learners in grade 4 have to be exposed to stimuli in order to aid retention.

Appropriate touch items, or benign items, as assessed by Liang, Bogat and McGrath (1993), do not typically improve significantly after participation in a programme, and in a cluster analysis, these authors concluded that the items appear conceptually unrelated to items about skills in sexual abuse situations. Blumberg, Chadwick, Fogarty, Speth and Chadwick (1991) developed research with seven vignettes (four dealing with appropriate touch and three dealing with inappropriate touch). Although the children in their study knew much of the information regarding inappropriate touch at pre-test, they had difficulty identifying appropriate touch. After participating in a prevention programme, these children significantly improved their ability to identify appropriate touch. Thus it may be that knowledge about appropriate touch constitutes a different variable than knowledge about inappropriate touch and should be assessed separately. The researcher agrees with Blumberg and colleagues in saying that knowledge about appropriate touching possibly constitutes a different variable than knowledge about inappropriate touching. Separate assessment is recommended by the researcher as well.

\section{Inappropriate Touch Subscale}

According to Table 7, there are significant differences between the improvement of knowledge within the experimental group's pre-, post- and follow-up tests on the Inappropriate Touch Subscale. There is thus a significant difference in knowledge between the pre- and post-tests, the post- and follow-up tests, as well as between the pre- and follow-up tests. There was a significant increase in knowledge from the pre-test to the post-test. The HOOC board game was implemented as intervention between the pre- and post-tests. There was also a significant increase in knowledge on inappropriate touching from the pre-test to the follow-up test six weeks later, thus indicating that the learners possessed more knowledge than before they were exposed to the HOOC board game. There is a minor decrease in knowledge between the postand follow-up tests, but it is of no statistical significance. Tutty (1997:869-880) administered the CKAQ on 231 children to determine whether an elementary school-based prevention programme was effective. The post-test's results - namely that the children who received the programme increased their knowledge on both the Appropriate and Inappropriate Touch Subscales to a more significant degree than the control group - confirms the findings of Tutty.

These results have several implications for the present study. Since it seems that Grade 4 learners' knowledge on appropriate and inappropriate touching decreased after six weeks, the researcher is of the opinion that preventive programmes or preventive stimuli need to be repeated on a regular basis. Grade 4 learners need to be exposed to these stimuli on a frequent basis to keep them alert and informed. The researcher is concerned that knowledge on appropriate touching decreased, as this is vital information the learners need to possess. It may be that children may overreact to inappropriate touch through the generalisation of perfectly appropriate situations to inappropriate situations. It also seems, from the abovementioned results, that the HOOC board game has a slight tendency to empower learners more on inappropriate touching than on appropriate touching. This may be due to the fact that learners tend to discuss inappropriate ways and situations more frequently than the appropriate ones. 


\section{The pre-test and follow-up test scores for the control group}

According to the obtained results in Table 7, there was a significant decrease in knowledge of body awareness on the Appropriate Touch Subscale for the control group. One would expect that knowledge on both the scales will decrease in a period of six weeks without any interventions. However, there was a significant increase in knowledge of body awareness on the Inappropriate Touch Subscale. It thus seems that the control group was positively influenced on the inappropriate touch knowledge, although no interventions were implemented. A possible explanation may be that the pre-test stimulated some children to search for correct answers to those questions they may have answered incorrectly, by asking others, or by paying special attention should they come across such information. These results are confirmed by Tutty (1992:380), who tested 400 children in four groups with the CKAQ, still unrevised at that stage, of which half of the sample participated in a prevention programme. The knowledge of the children who had no exposure to the programme changed substantially from the pre-test to the follow-up test after five months on the Appropriate and Inappropriate Touch Subscales. Similar findings in another study conducted by Tutty (1997:874) confirm the results that the control group's knowledge on both the Appropriate Touch and Inappropriate Touch Subscales improved as well.

\section{The follow-up test scores for the experimental and control groups}

The results obtained in Table 9 indicate a significant difference in knowledge improvement on the two subscales within the control and experimental groups. The follow-up test scores indicate that on the Appropriate Touch Subscale the experimental group scored significantly higher than the control group. On the Inappropriate Touch Subscale the experimental group also scored significantly higher than the control group. Thus, six weeks after the HOOC board game was implemented the experimental group had significantly more knowledge on appropriate and inappropriate touching than the control group.

Oldfield, Hays and Megel (1996:821-832) used the CKAQ-R to assess the effectiveness of project TRUST, an elementary school-based victimisation prevention strategy, and found that the experimental group demonstrated significantly greater knowledge of maltreatment prevention information than the control group. The improvement of knowledge after the implementation of a preventive intervention between pre- and follow-up tests for the age group of 9 to 12 years old confirms the findings of Hazard, Webb, Kleemier, Angert and Pohl (1991), Oldfield et al. (1996), Taal and Edelaar (1997).

However, Hazard et al. (1991) concluded in their study that during post-testing there were no significant differences between the intervention and control group children's ability to demonstrate prevention skills, such as saying "no", leaving and telling someone. At the 1-year follow-up children who participated in the programme the previous year, whether with or without a booster session, showed a significant increase in knowledge of CSA. As the followup testing for the present study was conducted after a relatively short period of six weeks, the researcher recommends that the follow-up testing needs to be conducted after a longer period.

As the HOOC board game is developed to be age-appropriate and to address the specific developmental phase of Grade 4 learners, the researcher is convinced that the appropriateness of the board game is a contributing factor to the improvement of knowledge of body awareness. As Shapiro (1998:115) states, developmental factors are important to consider in planning methods of communicating prevention information and skills. Younger children need to have ideas presented in simple language, in a concrete rather than abstract manner, and with lots of examples. For younger 
children, learning is often easier and less anxiety-producing when material is presented through play or imaginative activities. The HOOC board game incorporates all these facets.

The experimental group's knowledge of body awareness after the implementation of the HOOC board game did improve significantly between the pre-, post- and follow-up tests. These findings support the effectiveness of the HOOC board game as a strategy to increase prevention knowledge.

\section{The reliability of the CKAQ-RIII}

The CKAQ-RIII, an American standardised questionnaire, has strong psychometric properties within the Western context. It was imperative to determine its reliability within the unique South African context.

There is a significant relationship between the pre-, post- and follow-up tests for the Appropriate and Inappropriate Touch Subscales within the experimental group. It thus seems that the CKAQ-RIII provides reliable and accurate measures on the two subscales within the South African context. Working with more than one ethnic group is a challenging task as several other factors must be accommodated. One must never assume that what applies for one cultural or ethnic paradigm works exactly the same with another. The ideal would have been to use a South African standardised questionnaire for the study. There are, however, only a few standardised measures available to assess knowledge gain with respect to child abuse prevention concepts. Therefore an American standardised questionnaire had to be used. Since there are strong psychometric data available on the CKAQ-RIII, the researcher explored the psychometric properties within the South African context. The researcher urges further investigation concerning the validity and reliability of the CKAQ-RIII within the South African context.

\section{CONCLUSION}

According to the results obtained, the HOOC board game had a stronger impact on the scores of the Inappropriate Touch Subscale in both the experimental and control groups than on the Appropriate Touch Subscale. The possibility could therefore be investigated that the HOOC board game has a tendency to more strongly influence the learners' knowledge on inappropriate touching than on appropriate touching. As inappropriate touching is the core of preventative concepts, this does not constitute a problem.

The retention of knowledge among grade 4 learners is another important aspect. The results indicated that there tends to be a decrease of knowledge, especially on the appropriate touch subscale, within a six-week period. Although the decrease in knowledge is not of statistical significance, it still indicates a suggestion on the frequency of exposure of preventative concepts to Grade 4 learners. Grade 4 learners need to be exposed to preventative concepts on a regular basis to avoid a decrease in knowledge on personal safety measures and to maintain a sense of alertness. The researcher is not advocating that Grade 4 learners need to be exposed to a comprehensive prevention programme every six weeks, but rather suggesting that preventative concepts should be integrated into the curriculum. Considering the overall results of the study, the use of the HOOC board game as preventative measure against the sexual abuse of Grade 4 learners is acceptable. In addition, the CKAQ-RIII yielded reliable and accurate measures on the two subscales within the South African context. 


\section{REFERENCES}

BLUMBERG, E., CHADWICK, M., FOGARTY, L., SPETH, T. \& CHADWICK, D. 1991. The touch discrimination component of sexual abuse prevention training: unanticipated positive consequences. Journal of Interpersonal Violence, 6:12-28.

COREY, G., COREY, M.S. \& CALLANAN, P. 1993. Issues and ethics in the helping professions. California: Brooks/Cole.

DAVIS, L. \& CAMPHER, L. 2008. The prevention and control of youth misbehaviour in South Africa. In: BEZUIDENHOUT, C. \& JOUBERT, S. (eds) Child and youth misbehaviour in South Africa: a holistic approach $\left(2^{\text {nd }}\right.$ ed). Pretoria: Van Schaik Publishers.

DE VOS, A.S. (ed). 2002. Research at grass roots: for the social sciences and human service professions $\left(2^{\text {nd }}\right.$ ed). Pretoria: Van Schaik Publishers.

DE WITT, M.W. 2009. The young child in context: a thematic approach. Pretoria: Van Schaik Publishers.

DUNN, M. 2004. The development of a board game as preventative measure against the sexual abuse of grade four children. Pretoria: University of South Africa. (Doctoral dissertation)

GEORGE, D. \& MALLERY, P. 1999. SPSS for Windows: step by step. Boston: Allyn and Bacon.

HANEKOM, T. 2002. Hands off our children (HOOC) business plan: a marketing and communication strategy $\left(2^{\text {nd }}\right.$ Draft). Cape Town: Directorate Crime Prevention, Department of Community Safety.

HANEKOM, T. 2003. Assistant Director: Social Crime Prevention, Department of Community Safety. Personal interview. 10 March, Cape Town.

HAZARD, A., WEBB, C., KLEEMIER, C., ANGERT, L. \& POHL, J. 1991. Child sexual abuse prevention: evaluation and one year follow-up. Child Abuse \& Neglect, 15:123-138.

LEWIS, S. 1999. An adult's guide to childhood trauma: understanding traumatized children in South Africa. Cape Town: David Philip Publishers.

LIANG, B., BOGAT, A. \& McGRATH, M. 1993. Differential understanding of abuse prevention concepts among pre-schoolers. Child Abuse \& Neglect, 17:641-650.

LOFFELL, J. 2000. Toward effectiveness in services for sexually abused children in South Africa: some observations from a longitudinal study. Child Abuse Research in South Africa, $1(1): 6-11$.

MARSHALL, A. \& HERMAN, V. 2000. Child sexual abuse in South Africa $\left(2^{\text {nd }}\right.$ ed). Cape Town: LP Printers.

McGREGOR, D. 1993. A high school guidance programme aimed at the primary prevention of sexual abuse of children as part of a national strategy for the prevention of child sexual abuse in South Africa. Grahamstown: Rhodes University. (Doctoral dissertation)

MOUTON, J. 1996. Understanding social research. Pretoria: Van Schaik Publishers.

OLDFIELD, D., HAYS, B.J. \& MEGEL, M.E. 1996. Evaluation of the effectiveness of project trust: an elementary school-based victimization prevention strategy. Child Abuse \& Neglect, 20(9):821-832.

ROTHMAN, J. \& THOMAS, E.J. 1994. Intervention research: design and development for human service. New York: Haworth. 
SCHUTTE, I. 2000. The prevention and early detection of sexual abuse. Child Abuse Research in South Africa, 1(2):8-11.

SHAPIRO, J.P. 1998. Psychotherapeutic utilization of prevention education in treatment for sexually abused children. Journal of Child Sexual Abuse, 7(2):105-121.

SPIES, G.M. 2006. The effect of sexual abuse on a child. In: SPIES, G.M. Sexual abuse: dynamics, assessment and healing $\left(1^{\text {st }}\right.$ ed $)$. Pretoria: Van Schaik Publishers.

STRYDOM, H. 2002. Ethical aspects of research in the social sciences and human service professions. In: DE VOS, A.S. (ed) Research at grass roots: for the social sciences and human service professions $\left(2^{\text {nd }}\right.$ ed). Pretoria: Van Schaik Publishers.

STRYDOM, H. \& VENTER, L. 2002. Sampling and sampling methods. In: DE VOS, A.S. (ed) Research at grass roots: for the social sciences and human service professions ( $\left.2^{\text {nd }} e d\right)$. Pretoria: Van Schaik Publishers.

TAAL, M. \& EDELAAR, M. 1997. Positive and negative effects of a child sexual abuse prevention program. Child Abuse \& Neglect, 21(4):399-410.

TUTTY, L.M. 1992. The ability of elementary school children to learn child sexual abuse prevention concepts. Child Abuse \& Neglect, 16:369-384.

TUTTY, L.M. 1994. Developmental issues in young children's learning of sexual abuse prevention concepts. Child Abuse \& Neglect, 18(2):179-192.

TUTTY, L.M. 1997. Child sexual abuse prevention programs: evaluating "Who do you tell". Child Abuse \& Neglect, 21(9):869-881.

TUTTY, L.M. 2000. What children learn from sexual abuse prevention programs: difficult concepts and development issues. Research on Social Work Practice, 10(3):275-300.

VAN NIEKERK, J. 2006. The often neglected side of the sexual abuse equation - the child sex offender. In: SPIES, G.M. (ed) Sexual abuse: dynamics, assessment and healing. Pretoria: Van Schaik Publishers.

WILKINSON, W.K. \& McNEIL, K. 1996. Research for the helping professions. Pacific Grove, CA: Brooks/Cole Publishing Company.

Dr Munita Dunn, Deputy Director: Centre for Student Communities, Stellenbosch University, Stellenbosch, South Africa. 